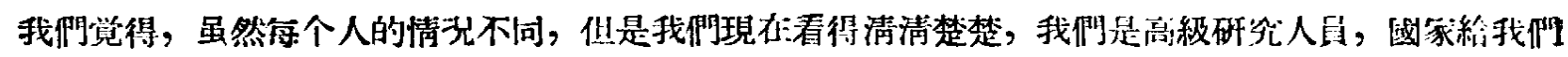

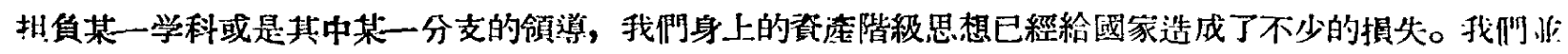
不鿌意使國家的事紫遭受損失，然而这已經是事实。我們現在只好从运动当中好好地吸取教訓。

現在我們还在考虑今后怎么办的問題。上海十七位科学家的倡議給了我們很大的㤵發，我們完全问意

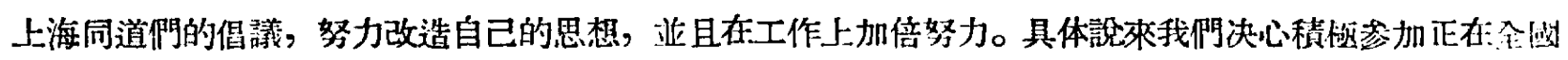
淮行的反泿費反保守比先進比多快好省地建設㪴会主义运动。像我润这样在旧的社会長大的, 受了这么長

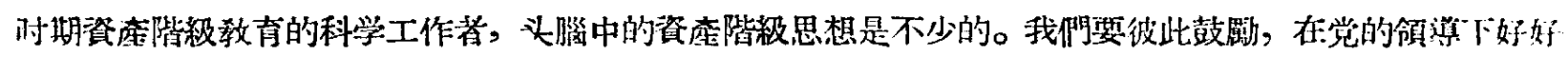

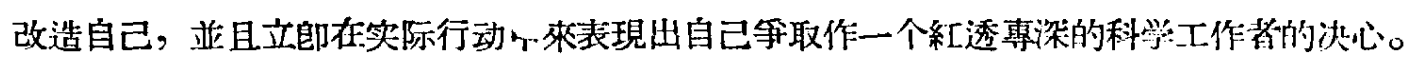

我門的这些想洪也还不透徽，肴整得到朋友們的批評。

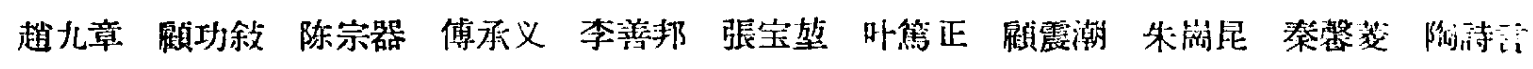

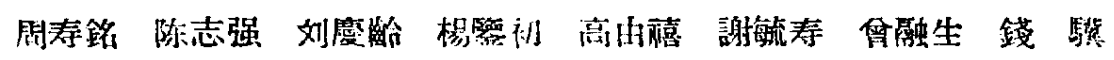

\section{躍 進}

浪潮, 一个接着一个。要紅, 要紅透; 装専, 要 專深。这是科学工作者思想的大解放、大躍谁, 只有 思想躍淮了，工作才能躍淮。有了思想的躍進，也就 必然会有科学工作的大躍進。

例如, 中國科学院林罂土壤研究所微生物室重新 討了工作計划, 原訂五年訃划门1 1958-1961 年研究工 作的主要部分，現在將在一年內完成。

例如, 中國科学院石油研究所提出了等取傮我國 的頁岩油、水煤气合成、煤焦油等人造石油的科学技 術水平在 5-7 年內赶上或超过國际水作。在我國的天 然石油的科学技術方面，要提前二年超指标完成國家 科学規划的既定任务。

例如，中國科学院上海实驗生物研究所，按照研
究題目要新安排了力量，加快了工作淮度，改愎了与

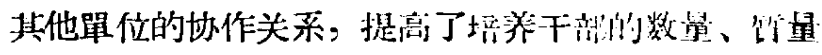
和速度, 出現了一片新的气象。

例如，中國科学院地行研觉所，科学家提出了装 將培养青年干部成为能独立工作並且还能带徒弱的期

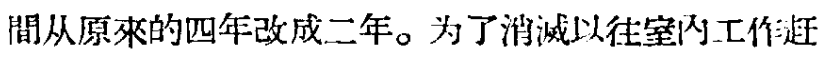

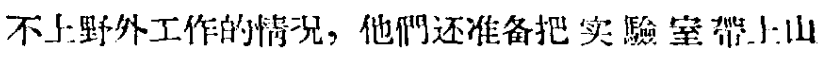
去。

先進的事例在不断地洦現。

这还只是一个开头。比光進, 比平勁, 比多快好

省! 接着來的將是更多的先淮事例, 更大的躍進!

乘風破泿，奋勇前淮!

\title{
爭取科学工作的大躍进 一記中国科学院研究所所长会竓
}

“科学工作能够躍进, 科学工作必須躍进 ${ }^{n}$ - 这 是中国科学院在北京召开的研究所所长会議上与会科 学家和科学領导干部的共同語言。这个会議从 2 月13 日起, 举行了 3 天。

郭洙若院长在会上作了題为“科学界的精市总动 員”的重要报告。他号召科学工作者拿出吃奶的气力 来, 促使科学大躍进。他說, 柽过所有制的革命和政 治思想战上的形会主义革命的伟大胜利，全国人民 的革命干劲好比原子核分裂一样發揮出無穷無尽的伟 大力量, 层起了空前热烈的生产高潮。随着工农業生 产的躍进，国家各个方面的事業也起了“錐鎖反应”而 在飞踓前进。这就要求我們科学工作也来个躍进，而 且科学的發展应当努力走在生产的前面去。觙沫若指
出在两年之前, 党中央提出的 “向科学进軍”及“孚取 在十二年內在某些急需的和重要的科学部門接近和赶 上世界先进水平”的口号, 䇉是要求科学大踓进的伟入 号召。两年来,在党和政府的領导下,我国科学工作者 已經为科学躍进准备了相当周到的条件: 制定了科学 發展的远景规划，㚘且根据这个規划制定了科学院的 第二个五年研究工作計划和1958年研究工作計划; 远 景規划正在逐步实現，特別是有关新技术的紧学哔施 正在大力进行; 国务院設站了科学梘划委目会, 做了 很多科学协調和組糡工作; 加强了科学队伍, 科学工 作者人数已有显著的埇长; 經过整風和反右派斗尔, 科学工作者的思想觉悟已有很大进步; 加强了和苏联 及其他兄弟屋家的合作，特另湜最近中苏两国政府和 
两国科学院、高郄部、农業科学院之開分别签訂了科学 工作的合作协議，标志了中苏两国科学方面的合作發 展到一个新阶段。郭沫若說, 有了这样比較充分的准 备, 在今后科学工作的狆展上来一个大躍进是大有希 望的。国家第一个五年計划已經超額完成，工农業生 产有了惊人的大躍进，这一方面能够为科学研究工作 提供更多更好的技术装备, 同时文要求科学事業迅速 㺕是，支援国家建设的需要。現在不应該是愁 “英雄 無用武之地”，而是愁“地無用武之英雄”，愁我們的英 雄太少了。

杼沫若院长还能励科学工作者要以“鼓起于劲, 多 快好省，一心一德，又紅又专，重視劳动，服从組織， 加强合作，实現兒划”这八句話作为共同的行动口号， 一鼓作气，趁热打鉄，伐我們科学事業乘風破浪地飞 䠛前进。

在会議上，忖潤生副秘書长报告了中国科学照代 表团赴苏商談的情况。杜潤生說，按照这次签訂的中 苏两国科学院 1958-1962 年合作議定書和 1958 年的 合作协議，苏联科学院寉年将为我国培养一百多名研 究干部, 还将派遺許多优秀的科学家来华指导和帮助 我們开展研究工作。同时今后两院和双方性質相近的 研究机构可以直接交換和协調研究計划，交流研究成 果。杜潤生在报告中还特別詳細地介維了苏联科学四 十年来發展的經过。他說，由于帝国主义的侵略和內 战的破坏，在苏維埃政权最初的十年中，苏联科学事 業的物質条件極㟨困难，人才少，又处在国际上孤立 無援的地位，但最終还是克服了重重团难而迅速签展 起来。特別是在第二次世界大战后，更是有惊人的登 展：荻联科学現在在許多重要方面已經躍居世界的首 位。杜潤生說，我国科学工作今天所处的条件比荻联 初期优越得多了。八年来已經生长起来一大批科学工 作者，仅是中国科学院全部工作人員已有一万七千余 人，国家又有充分的物質条件来支持科学事業的需 要，再加苏联的覓私的大力的援助，我国科学事業的 躍进和在今后十年左右健某些急需的、重萍的部門赶 上和接近世界先扫水平是完全可以做到的。

参加会議的科学芜，还听取了腙沫若院长传达毛 主席的指示和㑡交副秘書长传达周总理对文教工作的 指示。所有与会的同志都受到極大的站舞，紛紛表示 要弡揮高度的革命干到，有坚强的信心克服一切困 难, 促使我国科学事業大躍进。光受精泌机械仪器研 究所到所长散祖阔在大会登言中提出要“苦干五年， 爭取提前两年（即在八年內）在光学精密机械仪器的 主要方面赶上世界先进水平”。他說，在过去五年中我 国的光学工業、机峨工業已經有了长足的發展，我国 人民文有精巧的手工艺的传統，这些都是郋展光学精
樒机械仪器科学的重要条件。我们典在最近的五年內 掌握几个先进典型仪器的設計制造技术及其有关理 論，其中主要的是紅外光譜仪、光桐光譜仪、万能工 具显微踥、金相、位相显微鏡、高級电子显微鏡以及 国內需用的光学材料。然后再进一步例造新仪器。石 油研究所所长张大显說，在五年、十年之后，我国在 頁岩油、水煤气合成石油生产方面将远远超过英国、 西德和美国，这两方面的科学研究工作自然也应达乵 国际水平。少数民族語言研究所副所长傅愁勒馀，資 本主义国家里不可能真正帮助少数民族撥展語言 文 学，我們在这个問題上已經大火超过了資本主义国家 的水本。現在我們已經帮助少数民族設計了 21 种 文

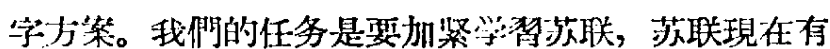
70 多个民族文字在迅速地發展着。科兴家們充滿着乐 覌主义的精砸。他佃表示，要把这个躍进大会的粘神 带问去，龉起夽体干部的干劲，在党的領导下，济心 协力, 实現我国科学事業的大躍进。

許多科学芜的腾言中都一政强調科学工作者的思 想躍进是科学躍进的前提。物理研究所所长䤵三强 說，我們这一代科学家，大抵是从脫离实际，“为等术 而学术” 的环境中长大的，而我們恰恰又担負举指导 和組織我国科学事業的重要点任，我狮的思想收造是 科学躍进的一个最重要的前提。他报告了物理研究所 检查加速器建造工作的結果。这次检查表明：科学家 的思想改造好了，改进了作風，研究工作的效等是可 以人大提高的。地球物理研究所所长赵九章說, 要做 到思想躍进，梁做好科学家的思想改造，就必須在科

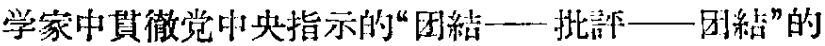
公式，要使科学家相互之間做到思想見面，把心交給 組織。过去有的人是貌合被离，表面上互相焦重，实 际上是“文人相輕”，口头上是为了社会主义，实际上 还是以“我”为中心。这是人民內部的两条道路的斗 争，我储要以社会主义思想来改造資本主义个人主义 思想。錢学森說，只要我們能够拊上工人阶新的没， 把每:个人的心交給䒔亿人民，那么我們钫个人就有六

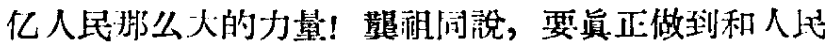
平等相处, 把心交給同志、交給組織。一定裂反对“万万

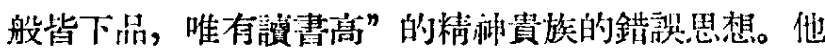
說由于知識藏在人的头脑里不能机械地挖治来，所以 这是“私有制”的最后藏身之地。知識本来是人民侧造 出来的，知識分子的知識是受觉和人民的培养行得来 的，因此知識分子不应当成为一个拥有多少 知 識的

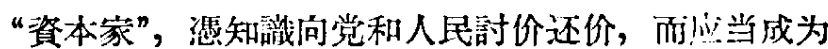
一个爱护这种公期財产——科学知識的忠实保㴪员, 应該把知識看成是全民所有的，是为全民服务的。

科学家在梫部中都認为科学事業必須在党的管导 
下才能躍进，没有党的領导，科学研究工作裉会迷失 方向，就会被資本主义思想把我們的工作搞的乱七八 糟。西北农業生物研究所副所长王有英說，今后应当 进一步采取措施树立和巩固党对科学工作的領导，使 我們的工作走塥会主义的道路，走多、快、好、省的 道路。錢三强說，㮒过整風和反右派斗争之后，絕大 多数科学家对于党对科学事業的政治、思想方面的領 导是沒有疑問的了，但是对于学术領导方面党能不能 掌握起来，有些人还是存在怀疑的。他說，学术領导 的主要內容应当是指分辨那件事情对，那件 事情不 对，应当支持那一和方案和在什么程度上加以支持。 党体靠正确的馬克思列宁主义思想覌点和群众路綫的 方法，是可以做到这一点的。八年来，我国科学事業 的順利墢展就是最充分的証明。当然专業知識不足的 党員同志, 应当下苦功鑽研業务, 由外行变成內行, 这样就可以更好地領导科学事業向前發展。

錢学森在發言中特別提出为了笑現我們的科学躍 进，我們就应該把眼光放远一些，不仅要看到国绿当 前的需要，而且要看到經过十年以至更长的时闑以后 的国傢的需要和科学的展状况。农業展綱姴四十 条可能要提前实現，我們科学工作者应当現在就西始 考虑这四十条实現以后，农業生产还应当如何向前㡎 展。他說，以后的农業墢展，不仅是机械化、电气 化、化学化的問題，而是如何把工程技术应用到农業 上去, 使农業生产也成为一个工厂似的，就是在控制 的条件下进行生产，这地可叫做农業的工業化。再 如，我們現在使用的能，主要是靠烧煤得来，炼鉄地 是用煤作还原剂。但是我們可以看到科学技术發展的 一个趋势，就是大量的能将是从水利来，以及或者是 裂变的原子能，或者是正在研究的氢聚变能，这些能 的最終出現形式就是电，因此我們应当考虑和重視使 用电的方法，而不是走燃料和煤的路。錢学栓还說， 科学院的条件特別适宜于發展新的学科之間的边緣学 科。例如把物理学渗透到各个部門中去（如生物物理 等)。这不仅是指自然科学、技术科学的相互渗透, 而 且应当重親自然科学、技术科学渗透到社会科学部門 中去, 如把統計数学方法用到杜会科学中去, 以及工 程技术方面的工業經济等。这和相互渗透就有可能墢 展起新新的重要的学科。

許多科学家提出科学躍进必須策取一系列的具体 措施。王育英說, 应当重䫓和进一步加强科学研究工 作的計划性。西北农業生物研究所过去的情况就是題 目分散，力量分散，各搞一尝。例如“黃河中游水土流 失地区士地合理利用的研究”一題, 本来內容就很广, 由一位高被研究人員頜导两位青年在进行，就已感到

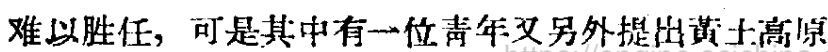

区合作谁提高农業生产途径的研究等两个題目，更加 影响了力量的集中使用。张大显和水生生物研究所王 家栮所长等人都强調了理論联系实际的重要案义。张 大显說，石油研究所在水煤气合成方面，几年冰已經 取得了一定的成綪，工業部門和国家計委拟按此方泣: 扩大生产，可是在1956年刮起了一股“唯有理諭富”的 歪風，原来从事这方面工作的同志也就放弃已获得的 成就不再繼續进行工作了，而另外开設四个所调理洨俞 性的題目。經过这次整風, 在所內展开了大辩諭, 这 几位同志已經感到那样做是不要当的，是脽缡实际， 鑽到牛角尖去“提高理諭水平”，因此重新开設了一-个 研究題目，把以往已获得的成果粰續加以深入的呼究 和提高，把四个“理諭性”的題目的研究規模适当地維 小了。这样做之后，四个月来，又已經取得很显著的 效果。王家楫說，我們要越設䀡会主义，过去底子是 又穷又白，因此科学研究工作要从实际壮發，强調理 論也是需要的，但理論不和笑际結合，理論既不能迅 速提高，而实际閣題又得不到解决。他說，水生生物 研究所近二年来的工作，江分虽調了理諭研究，和产 業部門合作不如以前那柊泌切了: 例如长江上游筑水

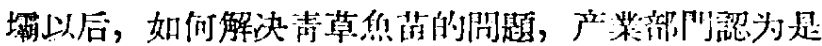
非常重要的，希望水生生物研究㰾协助研究解椥，可 是彭所投入的研究力量一直很少，这是不对的。在会

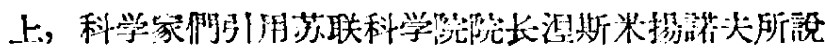

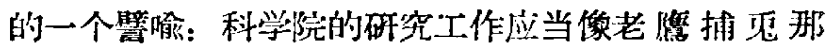

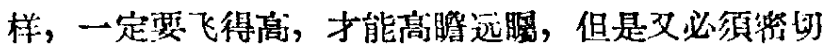
注哯地面的鬼子，飞得高，又看得准，才能有效，否 則飞高了，而目标渺茫，是不可能取得成績的。

中国科学院副院长、中共中国科学院党組書记张 劲夫在会議最后一天作丁他归納了会上大家的们 意見，提出了 24 个問題。张劲夫就，希望各研究机构 發动奔体工作人員研究和討論这些問題，渄备柇:今后

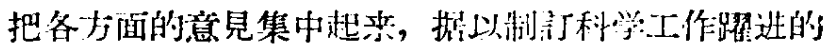
具体行动綱領。这些問題的主䓯文容是: 反右派斗等 之后，屬于敌我矛盾的晒条道路的斗争取得了基本泩

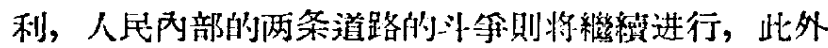
还裂进行“多快好省”和 “少慢度損”这两种方法的斗 争; 有需要又有可能时兴当爭取进一步改善条件、增 加力量, 但不能采取等微的态度, 肖先应当在現有条

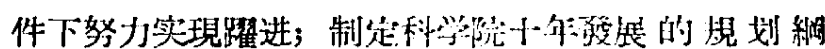
要; 科学研究工作要明确补会目的性，要道讨解决程 济交化建設中提出的任条来提高科学水水，而不是抽 象地提高水不; “重点發屡，全面安排”，合理地使阴 国家有限的人力、物力; 科学与技术沙切精合, 科学 工作要重視拄门用新的技术装备，丰以新的科学成果指

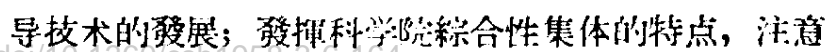


各个科学的相互渗透, 交文应前, 發展边緣科学; 各 研究机构立即着手修訂第二个五年計划; 在保証国家 任务的前提下，适当支援地方上所提出的科学任务; 坚持学㚙苏联，完成中茄两国科学院合作协議中所提 出的任务, 以及完成其他国际合作任务; 加强科学院 和高等学校、产業部門之間的合作，互相支援；进一 步整頓作風，改造思想，建立一支又縞专的科学队 伍; 科学工作者要做到思想見面，把心交給同志，把 心交給組織，消除“內耗”，加强团結; 科学工作者要 以晋通工人自居, 消灭“知識私有制”; 为了登展社会 主义和馬克思列宁主义，要繼續買徹白家爭鮚方跍，
批判資产阶級学术思想; 科学院各級領导干部要深入 基層, 检查和評比工作, 抓先进落后两头, 带动中間; 勤俭办科学; 科学工作中研究、技术（包括附痋工厂 生产)、行政三个系統要組成統一的有机体, 要批制 “唯 有研究高”的錯誤思想; 重頑培养各粐学术秘書 和 其 他科学組織工作人員; 依靠群众; 加强領导, 各研究 所所长首先要起統帅作用; 加速起草院章。

会議期間，还討論了如何組織笑現中荡㑂何目科学 院 1958 年合作协議問題及科学院 1958 年活点研究项 目的計划。

\section{科 学 与 社 会 至义 д. 巴諾夫}

最近，全世界的杂志和报紙都在談論关于苏联科 学成就的問題。不久以前，在資产阶級的刊物上还常 常出現这样的一些交章, 这些交章的作者对于获联人 民的不仅要赶上而且要超让国外的科学的願望加以諷

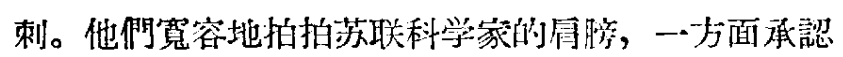
苏联有些数学家和物理学家还不錯, “汼不比酉方科 学家为差”, 一方面文說, 苏联的工程师“在西方只能 算作是好的技术人員”。

人造地球衛星的㡎射，使漗慣于上述这种覌点的 人产生了惊奇的印象。美国的反动报紙企圖貶低人造 街星郋射的意义，他剂說，只要願意，誰都作得到。 但是这是沒有用的。这样的論調使我們想起克雷洛夫 的“狐狸与蒱茠”这个著名的寓言。在这个寓言里，狐 狸怎么也拿不到蒲蓗, 它就說它根本就不想要, 它說 衡监是不錯, “但是还是青的, 小浆果还汥有成熟呢”。 美国海軍峧射“先鋒式”火箭遭到可耻的失敗以原，汶 些类似的論調就特別使人可笑了。

現在一切都很明显, 苏联科学家和工程师猚得了 这样的成就, 就是最墢达的資本主义国家, 現办比还 担当不了。那些迷信西方文明优越的人，对这个問题 感到很大的兴趣: 这是怎么一回事情呢? 在不久以前 还有相当根据可以認为苏联是在現代科学和技术的許 多方面是落后的国家，怎么能够获得这样惊人的成就 的呢?

对苏联人民来說，这是沒有什么可以命怪的。加 拿大詩人W - 麦克唐納从苏联回到渥太华时曾經公正 地指出: “在俄国, 人造衛星是一件很自然的事情, 它 只不过是精神生活各个方面越来越多的成就之一。”

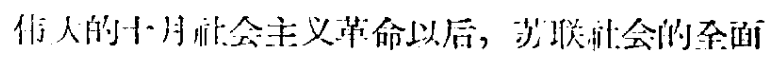

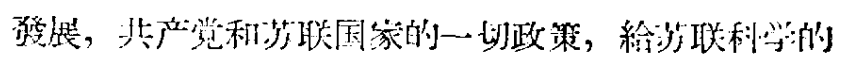
这个胜利以及其他很多的成战作了准备。这是很明具 的, 猉至对我僻沙联公民来說, 較詳紐地研究优苏联

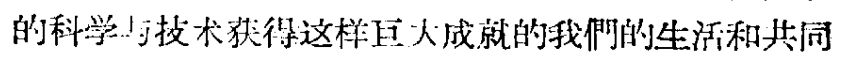
工作的排些力酒，还是值得的。

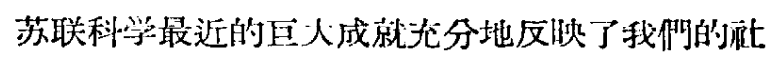
会主义制度，我們的經济、文化、馬克思列宁主义思 想較之資本主义制度及其經济、文化、思想具有無比的 优越性。缡会主义塥会, 按其本質来說, 汥有科学是 不可能發展起来的。社会主义汸上会是在工人阶粐領导 下的人民群众反对資本主义鞳命斗争中产生的。以最 先拈的科学理論一一馬克思列宁主义武装起来的尖产 党領导着人民的斗爭。实現这个先进的科学理論的思 想和絬論是無产阶級革命的胜利与社会主义新会在:我 国起成的一个很重要的条件。我僴的涼会今居的發展 仍然是以这个光进的馬列主义科学理論作为指战的。

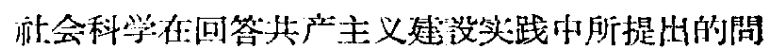
題的时候，它本身也在登展着。苏联科学家有研究和 总結新的生活現像时, 同时也研究了馬克思列挰:主义 哲学、政治經济学、历史学以及其他的閶題。然而, 在現在这箁論交里，仅仅利朋了与自然科学和技术科 学有关的一些資料，作为說明閏題的材料。

不論在城沛里, 不論在乡村里, 能会主义生产应 硋是，而实际上也确实是，建立在新的科学与技术成就 的基础上的。生产必須为了滿足全国人民的需要，而 不是为了滿足部会上的一部分“上底人物”的需要。必 